\title{
Evaluation of thin film composite forward osmosis membranes: effect of polyamide preparation conditions
}

\author{
Aya Mohammed Kadhom ${ }^{1}$, Mustafa Hussein Al-Furaiji ${ }^{2}$, and Zaidun Naji Abudi ${ }^{1}$ \\ ${ }^{1}$ Environmental Engineering Department, College of Engineering, Mustansiriyah University, Baghdad, Iraq \\ ${ }^{2}$ Environment and Water Directorate, Ministry of Science and Technology, Baghdad, Iraq
}

Correspondence: Mustafa Hussein Al-Furaiji (alfuraiji79@gmail.com)

Received: 11 October 2020 - Discussion started: 15 October 2020

Revised: 23 December 2020 - Accepted: 5 January 2021 - Published: 8 February 2021

\begin{abstract}
The forward osmosis (FO) process has been considered for desalination as a competitive option with respect to the traditional reverse osmosis process. The interfacial polymerization (IP) reaction between two monomers (i.e., m-phenylenediamine, MPD, and 1,3,5-benzenetricarbonyl chloride, TMC) is typically used to prepare the selective polyamide layer that prevents salts and allows water molecules to pass. In this research, we investigated the effect of preparation conditions (MPD contact time, TMC reaction time, and addition of an amine salt) on the FO performance in terms of water flux and salt flux. The results showed that increasing MPD contact time resulted in a significant increase in the water flux and salt flux. However, increasing TMC reaction time caused a decline in both the water flux and the salt flux. The optimum condition that gave the highest water flux $\left(64 \mathrm{~L} \mathrm{~m}^{-2} \mathrm{~h}^{-1}\right)$ was found to be as $5 \mathrm{~min}$ for MPD and $1 \mathrm{~min}$ for TMC. The addition of an amine salt of camphorsulfonic acid-triethylamine (CSA-TEA) was able to have an apparent effect on the FO process by increasing the water flux $\left(74.5 \mathrm{~L} \mathrm{~m}^{-2} \mathrm{~h}^{-1}\right)$.
\end{abstract}

\section{Introduction}

Water purification is the process of removing pollutants from raw water to produce water for human consumption (drinking water) or other beneficial purposes (irrigation, livestock, and industrial use; Maddodi et al., 2020). Membrane processes are among the most effective methods that can be used for water purification, especially for the desalination of water.

At this time, the most effective technique is the reverse osmosis (RO) process, where it can be used to desalinate seawater and also for wastewater reuse (Kadhom et al., 2019; Kalash et al., 2020). RO can be defined as the process that relies on external force, in which the applied hydraulic pressure is responsible for transporting water through the membrane (Peñate and García-Rodríguez, 2012).

Forward osmosis (FO) is an osmotically driven membrane process that uses the osmotic pressure gradient to drive water transport across a semipermeable membrane while rejecting most solutes (Cath et al., 2006; McCutcheon et al., 2005). In the FO process, water transports from a low osmotic pressure solution (i.e., feed solution) to a higher osmotic pressure solution (i.e., draw solution). Besides, FO has been considered a high water recovery and low-cost purification option compared to the pressure-driven membrane processes like RO (Linares et al., 2017). One of the most critical factors affecting the development of the FO process is preparing a suitable membrane for the process. The ideal membranes for FO have to be able to provide high water permeability, have a high rejection of solutes, substantially reduce internal concentration polarization (ICP), and have high chemical stability and mechanical strength (Ren and McCutcheon, 2014; Zhao et al., 2012).

Thin film composite (TFC) membranes have been studied widely for FO applications (Al-Furaiji et al., 2019; Chowdhury et al., 2017; Ren and McCutcheon, 2017). TFC membranes consist of two layers, namely a selective layer that only allows water to pass and rejects salt, and a support layer that gives the membrane the required mechanical properties. Most of the FO studies on TFC membranes have been focus- 
ing on developing the support layer, while fewer studies have been considering improving the selective layer.

The preparation of the polyamide selective layer is conducted using an interfacial polymerization (IP) reaction (Mohammadifakhr et al., 2020). Typically, the IP reaction occurs between two reactive monomers, i.e., m-phenylenediamine (MPD) in the aqueous phase with 1,3,5-benzenetricarbonyl chloride (TMC) in the organic phase (Raaijmakers and Benes, 2016). Previous studies have reported that controlling the IP reaction conditions could significantly affect the performance of the formed polyamide layer (Kadhom and Deng, 2019a); however, most of these studies were dealing with RO membranes (Dong et al., 2015; Jin and Su, 2009; Zhao et al., 2013). In contrast, very few studies have investigated the effect of the interfacial polymerization reaction on the performance of the TFC FO membranes (Klaysom et al., 2013). Therefore, studying the effect of the preparation conditions can help in preparing highly efficient FO membranes.

In this work, the effect of MPD aqueous solution exposure time and TMC organic solution reaction time is studied. In addition, the effect of incorporating an amine salt to the MPD solution was reported. This paper aims to study the conditions of the IP reaction on the efficiency of the TFC membranes in the FO process. Scanning electron microscopy (SEM), atomic force microscopy (AFM), and contact angles measurements were used to characterize the prepared membranes.

\section{Materials and methods}

\subsection{Materials}

Polysulfone (PSU; MW = 22 000) from Xian Lyphar Biotech Co., Ltd., Xian City, China, was used to fabricate the membrane substrates. N,N-dimethylformamide (DMF; $99.8 \%$ ) and 2,2,4-trimethylpentane (isooctane; 99\%) were purchased from Sigma-Aldrich Chemie GmbH, Buchs, Switzerland. MPD (>99\%) and TMC $(98 \%)$ were ordered from Merck KGaA, Darmstadt, Germany. Triethylamine (TEA; $\geq 99 \%$ ) and (1S)-(+)-10-camphorsulfonic acid (CSA; $99 \%$ ) were purchased from Sigma-Aldrich, St. Louis, Missouri, USA. Sodium chloride $(\mathrm{NaCl})$ was purchased from Thomas Baker (Chemicals) Pvt. Ltd., Mumbai, India. Deionized water (DI water) was used to prepare $\mathrm{NaCl}$ and MPD aqueous solutions and for other purposes such as cleaning.

\subsection{Preparation of PSU support layer}

The phase inversion method was used to prepare the PSU supporting sheets. The casting solution was prepared by dissolving $17 \mathrm{wt} \%$ dry PSU pellets in DMF. The mixture was stirred and heated to $60^{\circ} \mathrm{C}$ for $6 \mathrm{~h}$ until a clear solution was formed, which was then degassed for more than $24 \mathrm{~h}$ at room temperature before use. Afterward, the solution was cast, using a homemade casting knife, by taking an aliquot from the clear solution with a pipette to spread on a clean glass plate to the desired thickness. The glass plate with the solution was then immersed into a water bath at room temperature, resulting in the immediate formation of the PSU support sheet that was separated from the glass plate in a moment. Then, all of the sheets were collected and stored in DI water for $24 \mathrm{~h}$ or more at $4{ }^{\circ} \mathrm{C}$ before use.

\subsection{Preparation of TFC membrane}

TFC FO membranes were fabricated on the top surface of the PSU sheet by the IP reaction between the MPD aqueous solution and TMC organic solution. The MPD aqueous solution was prepared by dissolving $2 \%$ MPD in DI water, while the TMC solution was made by dissolving $0.15 \%$ of TMC in isooctane. First, the MPD solution was poured onto the PSU sheet at different contact times. Then, the TMC solution was poured onto the PSU sheet that contains the MPD active sites, and the reaction time was also varied to study the effect of IP reaction time. At first, the MPD contact time was varied from 2 to $5 \mathrm{~min}$, while keeping the contact time of the TMC at $1 \mathrm{~min}$. Then, the best MPD contact time (i.e. $5 \mathrm{~min}$ ) that gave the highest water flux was chosen, and the TMC solution contact time was studied in the range of 1 to $4 \mathrm{~min}$. In order to study the effect of adding CSA-TEA at a weight ratio of $2: 1$, they were added to the MPD solution with a weight of $1 \%$. The IP reaction was conducted at room temperature. Finally, the obtained TFC membranes were dried in the oven at $60^{\circ} \mathrm{C}$ for $10 \mathrm{~min}$ and then collected and stored in DI water for $24 \mathrm{~h}$ until testing.

\subsection{Membrane characterization}

A scanning electron microscope (Mira-3 FEG SEM, Tescan Orsay France S.A.R.L) and Atomic Force Microscope (Angstrom Advanced Inc., Stoughton, MA, USA) were used to determine the morphology of the prepared membrane. The hydrophilicity of the membranes was measured using contact angles (Theta Lite, TL-101; Ryts Instruments, Bangkok, Thailand).

\subsection{FO performance test}

The FO performance was tested in a bench-scale system, as shown in Fig. 1. This system consists of two tanks, with one being used for the feed solution and the other containing the draw solution. DI water was used as a feed solution, while $1 \mathrm{M} \mathrm{NaCl}$ was used as a draw solution based on the standard methodology that was described by Cath et al. (2013). These solutions were pumped to the membrane cell using two pumps from Pure Water Products, LLC, Denton, TX, USA (model - 75 GPD; volts - 24 VDC; workflow 28 LPH). All experiments were conducted in FO mode (i.e., active layer faces the feed solution). The membrane was installed in a custom-made cell with the chamber's dimensions 


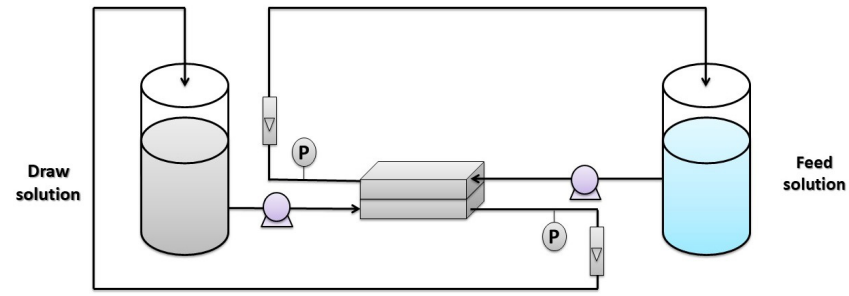

Figure 1. Schematic diagram of the FO bench-scale test unit (AlFuraiji et al., 2018).

of $7.62 \mathrm{~cm}$ length, $2.54 \mathrm{~cm}$ width, and a depth of $0.3 \mathrm{~cm}$. The water flux $J_{\mathrm{w}}$ can be estimated using the following equation (Al-Furaiji et al., 2018):

$J_{\mathrm{w}}=\frac{\Delta V}{A t}$,

where $J_{\mathrm{w}}$ is the water flux ( $\mathrm{LMH}$ is $\mathrm{L} \mathrm{m}^{-2} \mathrm{~h}^{-1}$ ), $\Delta V$ is the change in feed solution volume (L), $A$ is the active area of the membrane $\left(\mathrm{m}^{2}\right)$, and $t$ is the experiment's time (in hours).

Typically, salt flux is used in FO investigations to describe the selectivity of the membrane, while salt rejection is normally used in RO studies. The salt rejection equation can be used when there is a feed solution involved in the process, while in FO there is a feed solution and a draw solution. That is why the salt flux is used instead of the salt rejection. Salt flux through the membrane was estimated by monitoring the change in the conductivity of the feed solution and using the following equation (Al-Furaiji et al., 2020):

$J_{\mathrm{s}}=\frac{\Delta C V}{A t}$,

where $J_{\mathrm{S}}$ is the salt flux $\left(\mathrm{GMH}\right.$ is $\left.\mathrm{g} \mathrm{m}^{-2} \mathrm{~h}^{-1}\right), \Delta C$ is the change in the feed solution concentration $\left(\mathrm{g} \mathrm{L}^{-1}\right), V$ is the volume of feedwater flow (L), $A$ is the active area of the membrane $\left(\mathrm{m}^{2}\right)$, and $t$ is the experiment's time (in hours).

\section{Results and discussion}

\subsection{Membrane characterization}

The two dimensional (2D) and three dimensional (3D) AFM images of the top surface of the TFC membrane are presented in a scan area of $2500 \times 2500 \mathrm{~nm}$, as shown in Fig. 2. It can be clearly seen that the surface of the polyamide layer has a ridge-and-valley structure, with the average roughness of the FO membrane surface being $5.07 \mathrm{~nm}$. The surface roughness of the prepared membrane was quite similar to what has been reported for typical FO (Mi and Elimelech, 2008) and nanofiltration membranes (Li et al., 2017, 2020). The rougher surface could be more beneficial for membrane performance as it gives a higher area for mass transfer, especially when dealing with a low-fouling feed solution.
SEM images were used to investigate the surface morphology of the TFC membranes, as shown in Fig. 3. It can be seen that the polyamide selective membrane was successfully formed on the PSU support sheet. This was confirmed by the leaf-like morphology, which is a typical structure for polyamide TFC membranes (Kadhom and Deng, 2019b; Zhou et al., 2014).

Figure 4 shows the contact angle measurement of the PSU support membrane and the polyamide selective layer. The contact angle of the PSU sheet was about $65^{\circ}$, while the thin polyamide layer had a contact angle of $33^{\circ}$. The contact angle of the membrane can be influenced by many parameters such as monomer concentration, reaction time, type of organic solution, posttreatment condition, etc., during the IP reaction process. However, the reported value of the contact angle in this research lies within the range of the previously reported contact angle of the TFC membrane (Kadhom et al., 2016; Lau et al., 2015). When the contact angle is small then it means that the membrane is hydrophilic and that the water penetrates easily into the pores of the membrane, which gives a better osmotic water flux performance. Nevertheless, when the contact angle is large, it means that the film is hydrophobic, so the internal surfaces of the pores become dry, and that leads to a membrane with lower water flux.

\subsection{Effect of MPD exposure time}

After the PSU support sheet has been prepared, the active layer is prepared by pouring the MPD solution onto the PSU layer after attaching it well on a glass plate. The effect of the MPD exposure time on the performance of the TFC FO membrane was studied by varying the contact time from 2 to $5 \mathrm{~min}$ while fixing the TMC reaction time at $1 \mathrm{~min}$, as shown in Fig. 5.

The osmotic performance results revealed that water flux increases when the MPD exposure time increases. Also, increasing the MPD contact time leads to increasing salt flux. In fact, a higher MPD exposure time means more MPD molecules would react with the support layer and, accordingly, increase the IP reaction active sites. Moreover, wellformed cross-linking would be achieved at a higher MPD exposure time, which gives better IP reaction conditions when it reacts with the TMC later (Kadhom and Deng, 2019a).

\subsection{Effect of TMC reaction time}

In order to study the effect of IP reaction time, the TMC contact time was varied from 1 to 4 min by setting the MPD exposure time at $5 \mathrm{~min}$, as shown in Fig. 6. The TMC organic solution was poured on the PSU substrate that contains the MPD active sites to conduct the IP reaction. It can be seen that the optimum condition that gave the highest water flux was recorded at a reaction time of $1 \mathrm{~min}$. Interestingly, it can also be observed that the water flux and salt flux decreased sharply with the increase in TMC reaction time. 


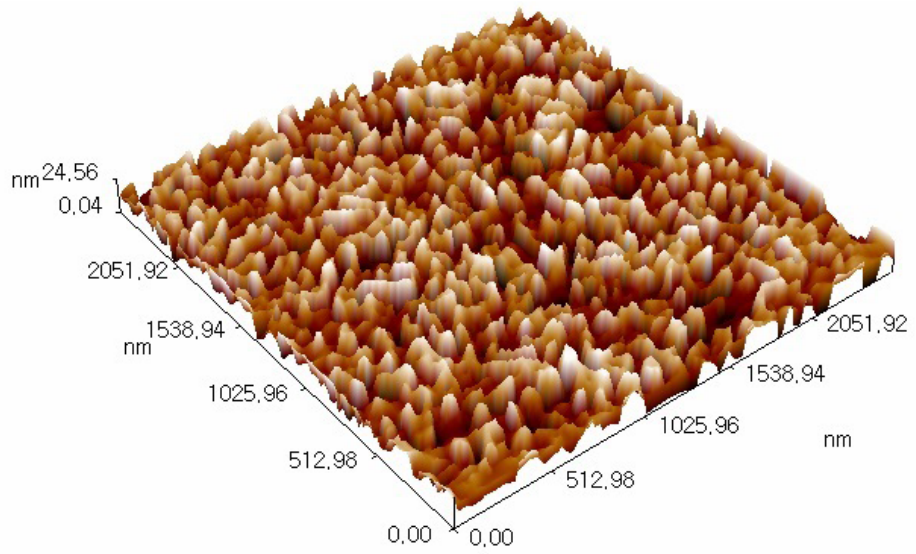

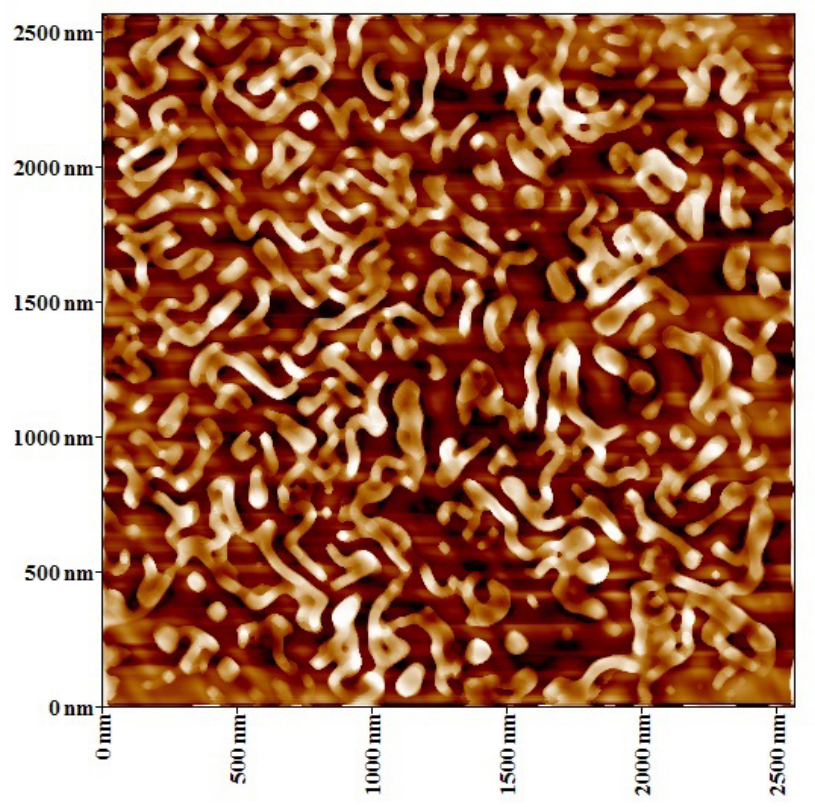

Figure 2. AFM images of the TFC FO membrane.

This is mainly attributed to the fact that increasing the TMC contact time leads to generating a thicker polyamide layer and, consequently, a higher mass transfer resistance to permeation of water (Zhou et al., 2014). Moreover, the extent of the cross-linking is increased with the increase in the IP reaction time, and as a result, water flux and salt flux decreased (Wang et al., 2017).

\subsection{Effect of CSA-TEA salt}

The effect the addition of amine salt (i.e., CSA-TEA) on the performance of the FO process was studied, as shown in Fig. 7. It has been found that adding $1 \%$ of the CSATEA to the aqueous MPD solution exhibited a moderate in-
CSPM Imager Surface Roughness Analysis

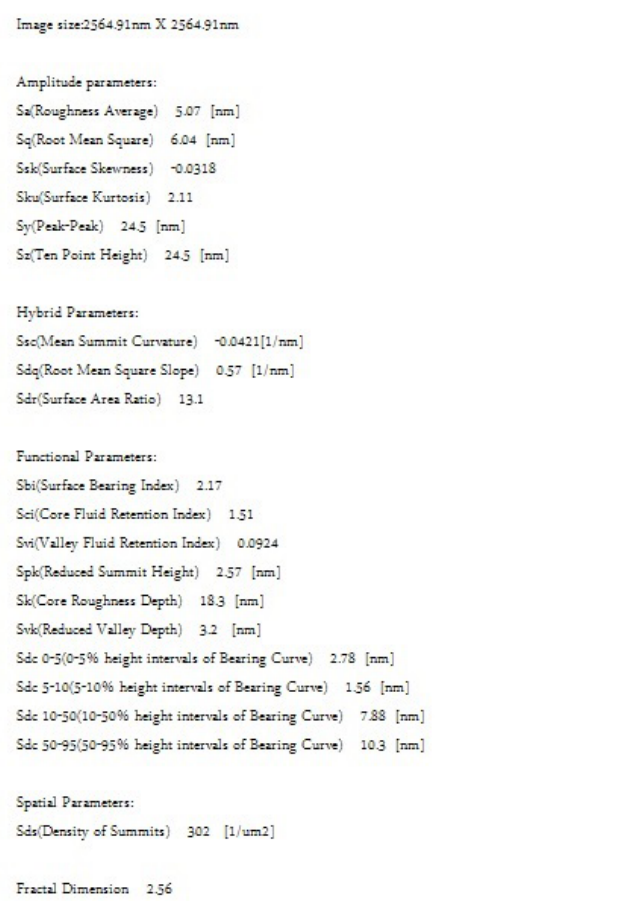

crease in both the water flux and salt flux. Similar behavior was reported for RO and nanofiltration processes (Khorshidi et al., 2017). It is known that polyamide formation during the IP reaction can result in the release of hydrogen chloride (Raaijmakers and Benes, 2016). The formation of hydrogen chloride can affect the reactivity of the monomer reactant in the aqueous phase (i.e., MPD). Therefore, the addition of a strong base such as TEA enhances the reactivity of the MPD and consumes the produced acid (i.e. hydrogen chloride). Also, it has been reported that the TEA acts as a catalyst by accelerating the MPD-TMC reaction and generating a thinner and more cross-linked polyamide layer (Vatanpour et al., 2017; Wang et al., 2017). 
Table 1. Comparison of the performance of some TFC membranes from previous studies.

\begin{tabular}{|c|c|c|c|c|c|}
\hline Membrane & $\begin{array}{l}\text { Feed } \\
\text { solution }\end{array}$ & $\begin{array}{l}\text { Draw } \\
\text { solution }\end{array}$ & $\begin{array}{r}\text { Water flux } \\
\left(\mathrm{L} \mathrm{m}^{-2} \mathrm{~h}^{-1}\right)\end{array}$ & $\begin{array}{r}\text { Salt flux } \\
\left(\mathrm{G} \mathrm{m}^{-2} \mathrm{~h}^{-1}\right)\end{array}$ & Reference \\
\hline TFC-PSU & DI water & $1 \mathrm{M} \mathrm{NaCl}$ & 36.58 & 6.8 & This work \\
\hline TFC-PAN & DI water & $1 \mathrm{M} \mathrm{NaCl}$ & 16 & 4 & Al-Furaiji et al. (2020) \\
\hline Aquaporin TFC & DI water & $1 \mathrm{M} \mathrm{NaCl}$ & 9 & 4 & Xia et al. (2017) \\
\hline TFC-M2 [cellulose acetate butyrate (CAB) substrate] & DI water & $1 \mathrm{M} \mathrm{NaCl}$ & 16.8 & 5.88 & Ma et al. (2020) \\
\hline Polyvinylidene difluoride nanofiber polyamide (PA) & DI water & $1 \mathrm{M} \mathrm{NaCl}$ & 11.6 & 3.48 & Tian et al. (2013) \\
\hline Polysulfone (PSU)/silica-PA & DI water & $1 \mathrm{M} \mathrm{NaCl}$ & 31 & 7.44 & Liu and $\mathrm{Ng}(2015)$ \\
\hline Oasys TFC & DI water & $1 \mathrm{M} \mathrm{NaCl}$ & 30 & 50 & Cath et al. (2013) \\
\hline
\end{tabular}
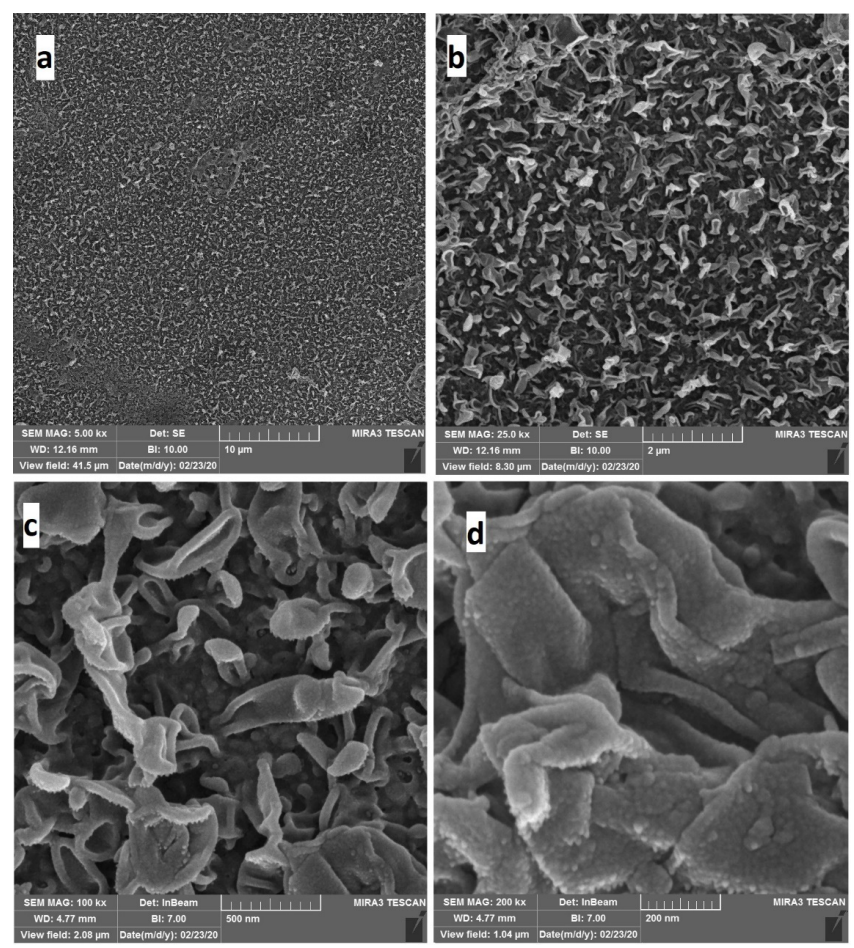

Figure 3. SEM images of the TFC FO membrane, showing the magnifications as follows (a) 5000X, (b) 25000X, (c) $100000 \mathrm{X}$, and (d) $200000 \mathrm{X}$.

\section{(a)}
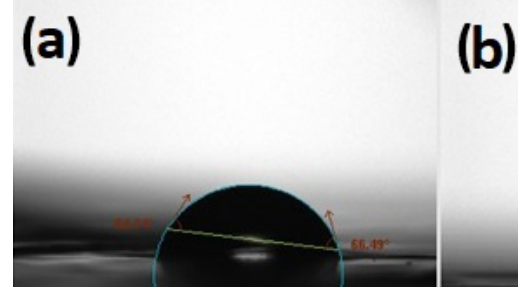

Figure 4. The contact angle of the (a) PSU substrate membrane and (b) polyamide thin layer.
A comparison of the TFC-PSU membrane with some of the previously reported TFC membranes can be found in Table 1. It can be seen that the TFC-PSU membrane exhibited the highest water flux compared to the reported membranes. However, the reverse salt flux value lies within the range of the previously reported salt flux of the TFC membranes. If we look closely to the results of our previous work (Al-Furaiji et al., 2020) and compare it to the current work, it can be distinguished that the water flux of the current work is about twice that of the previous work, while the salt flux is a bit higher. There are two main differences between the previous work (Al-Furaiji et al., 2020) and the current work, as follows:

1. In the previous work, we used a polyacrylonitrile (PAN) polymer as a support for the TFC FO membrane, while in this work we used a polysulfone (PSU) polymer.

2. In the previous work, the support layer was prepared using the electrospinning method, while in this work the phase inversion method was used.

The polyamide layer was perfectly formed and well distributed on the PSU support layer compared to the PANnanofiber-based membrane. This is most likely due to the smaller pore size and the hydrophobic nature of the PSU substrate. Although the electrospinning method produces a highly porous membrane, phase inversion makes a more robust membrane that can perform better in FO testing.

\section{Conclusion}

In this work, TFC FO membranes were prepared on PSU substrate (17 wt \%) as a support layer, via the IP reaction between MPD and TMC, to form a polyamide selective layer. The effect of the MPD and TMC reaction times was investigated. The best results were found to be at $5 \mathrm{~min}$ for MPD and $1 \mathrm{~min}$ for TMC reaction times. These results gave the best performance of the FO membranes in terms of water flux and salt rejection. Increasing the MPD exposure time leads to increasing the active sites on the PSU layer. By changing 

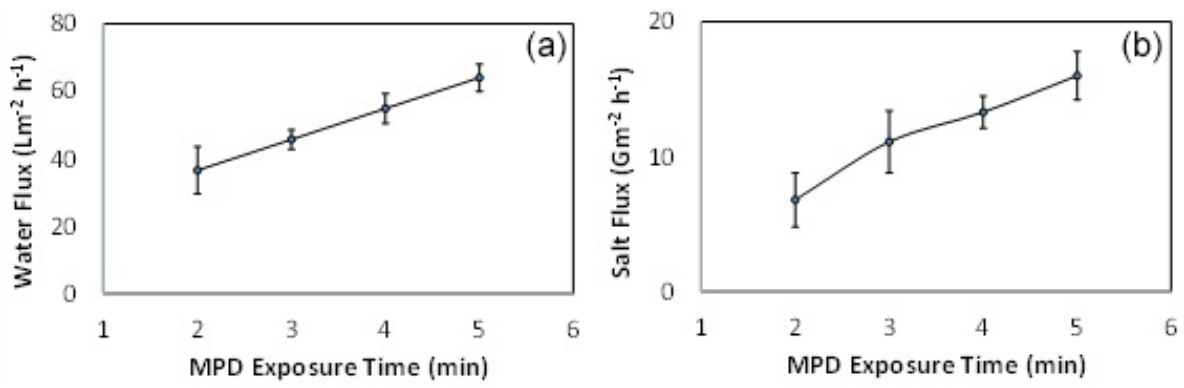

Figure 5. The effect of MPD contact time on membrane performance. The feed solution is DI water, and the draw solution is $1 \mathrm{M}$ NaCl. (a) The water flux (LMH) changing with different MPD exposure time (in minutes). (b) The salt flux (GMH) changing with different MPD exposure time (in minutes).
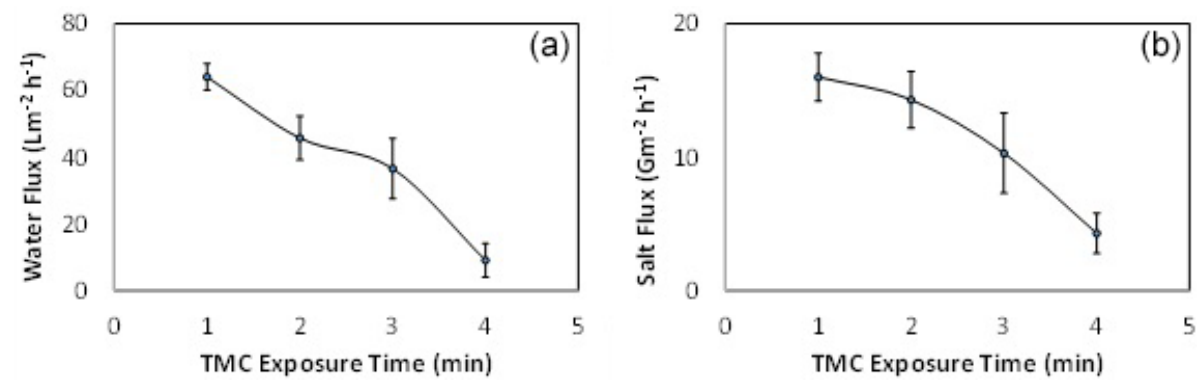

Figure 6. The effect of TMC contact time on membrane performance. The feed solution is DI water, and the draw solution is $1 \mathrm{M}$ NaCl. (a) The water flux (LMH) changing with different TMC exposure time (in minutes). (b) The salt flux (GMH) changing with different TMC exposure time (in minutes).
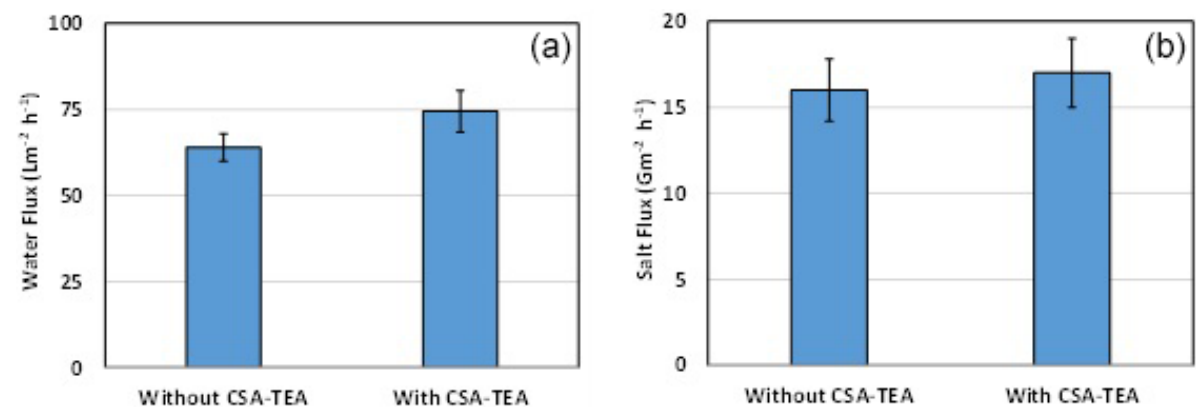

Figure 7. The effect of adding CSA-TEA to the MPD aqueous solution on the (a) water flux and (b) salt flux. The feed solution is DI water, and the draw solution is $1 \mathrm{M} \mathrm{NaCl}$.

the TMC reaction time, it is possible to control the denseness of the polyamide layer and, consequently, the amount of water and salt that passes through the membrane. Also, the effect of the addition of an amine salt (CSA-TEA) on the performance of FO membranes was demonstrated. The result showed that a moderate improvement in water flux was achieved. Finally, this study can be considered as a useful guide for researchers and workers in the field of preparing TFC FO. Future research can focus on investigating other additives to the MPD and TMC solutions. Also, studying the effect of changing MPD and TMC concentrations in preparing TFC FO is highly recommended for future works.
Data availability. No data sets were used in this article.

Author contributions. AMK wrote the first draft of the paper, conducted the experiments, and made the characterizations of the membranes. MHAF initiated the project, made editorial corrections, and prepared the figures and tables. ZNA reviewed the original paper and analyzed the obtained data.

Competing interests. The authors declare that they have no conflict of interest. 
Acknowledgements. The authors would like to thank Mustansiriyah University, Baghdad, Iraq, and the Ministry of Science and Technology in Iraq for supporting this work.

Review statement. This paper was edited by Luuk Rietveld and reviewed by two anonymous referees.

\section{References}

Al-Furaiji, M. H. O., Arena, J. T., Chowdhury, M., Benes, N., Nijmeijer, A., and McCutcheon, J. R.: Use of forward osmosis in treatment of hyper-saline water, Desalin. Water Treat., 133, 1-9, https://doi.org/10.5004/dwt.2018.22851, 2018.

Al-Furaiji, M., Benes, N., Nijmeijer, A., and McCutcheon, J. R.: Use of a Forward Osmosis-Membrane Distillation Integrated Process in the Treatment of High-Salinity Oily Wastewater, Ind. Eng. Chem. Res., 58, 956-962, https://doi.org/10.1021/acs.iecr.8b04875, 2019.

Al-Furaiji, M., Kadhom, M., Kalash, K., Waisi, B., and Albayati, N.: Preparation of thin-film composite membranes supported with electrospun nanofibers for desalination by forward osmosis, Drink. Water Eng. Sci., 13, 51-57, https://doi.org/10.5194/dwes13-51-2020, 2020.

Cath, T. Y., Childress, A. E., and Elimelech, M.: Forward osmosis: Principles, applications, and recent developments, J. Memb. Sci., 281, 70-87, https://doi.org/10.1016/j.memsci.2006.05.048, 2006.

Cath, T. Y., Elimelech, M., McCutcheon, J. R., McGinnis, R. L., Achilli, A., Anastasio, D., Brady, A. R., Childress, A. E., Farr, I. V., Hancock, N. T., Lampi, J., Nghiem, L. D., Xie, M., and Yip, N. Y.: Standard Methodology for Evaluating Membrane Performance in Osmotically Driven Membrane Processes, Desalination, 312, 31-38, https://doi.org/10.1016/j.desal.2012.07.005, 2013.

Chowdhury, M. R., Huang, L., and McCutcheon, J. R.: Thin Film Composite Membranes for Forward Osmosis Supported by Commercial Nanofiber Nonwovens, Ind. Eng. Chem. Res., 56, 10571063, https://doi.org/10.1021/acs.iecr.6b04256, 2017.

Dong, H., Zhao, L., Zhang, L., Chen, H., Gao, C., and Winston Ho, W. S.: High-flux reverse osmosis membranes incorporated with $\mathrm{NaY}$ zeolite nanoparticles for brackish water desalination, J. Memb. Sci., 476, 373-383, https://doi.org/10.1016/j.memsci.2014.11.054, 2015.

Jin, Y. and Su, Z.: Effects of polymerization conditions on hydrophilic groups in aromatic polyamide thin films, J. Memb. Sci., 330, 175-179, https://doi.org/10.1016/j.memsci.2008.12.055, 2009.

Kadhom, M. and Deng, B.: Synthesis of high-performance thin film composite (TFC) membranes by controlling the preparation conditions: Technical notes, J. Water Process Eng., 30, 100542, https://doi.org/10.1016/j.jwpe.2017.12.011, 2019a.

Kadhom, M. and Deng, B.: Thin film nanocomposite membranes filled with bentonite nanoparticles for brackish water desalination: A novel water uptake concept, Microporous Mesoporous Mater., 279, 82-91, https://doi.org/10.1016/j.micromeso.2018.12.020, 2019b.
Kadhom, M., Yin, J., and Deng, B.: A thin film nanocomposite membrane with MCM-41 silica nanoparticles for brackish water purification, Membranes (Basel), 6, 6040050, https://doi.org/10.3390/membranes6040050, 2016.

Kadhom, M., Albayati, N., Salih, S., Al-Furaiji, M., Bayati, M., and Deng, B.: Role of Cellulose Micro and Nano Crystals in Thin Film and Support Layer of Nanocomposite Membranes for Brackish Water Desalination, Membranes (Basel), 9, 101, https://doi.org/10.3390/membranes9080101, 2019.

Kalash, K., Kadhom, M., and Al-Furaiji, M.: Thin film nanocomposite membranes filled with MCM-41 and SBA-15 nanoparticles for brackish water desalination via reverse osmosis, Environ. Technol. Innov., 20, 101101, https://doi.org/10.1016/j.eti.2020.101101, 2020.

Khorshidi, B., Thundat, T., Pernitsky, D., and Sadrzadeh, M.: permeation properties of thin fi $1 \mathrm{~m}$ composite polyamide membrane, J. Memb. Sci., 535, 248-257, https://doi.org/10.1016/j.memsci.2017.04.052, 2017.

Klaysom, C., Hermans, S., Gahlaut, A., Van Craenenbroeck, S., and Vankelecom, I. F. J.: Polyamide/Polyacrylonitrile (PA/PAN) thin film composite osmosis membranes: Film optimization, characterization and performance evaluation, J. Memb. Sci., 445, 2533, https://doi.org/10.1016/j.memsci.2013.05.037, 2013.

Kwon, S. J., Park, S. H., Park, M. S., Lee, J. S., and Lee, J. H.: Highly permeable and mechanically durable forward osmosis membranes prepared using polyethylene lithium ion battery separators, J. Memb. Sci., 544, 213-220, https://doi.org/10.1016/j.memsci.2017.09.022, 2017.

Lau, W. J., Ismail, A. F., Goh, P. S., Hilal, N., and Ooi, B. S.: Characterization methods of thin film composite nanofiltration membranes, Sep. Purif. Rev., 44, 135-156, https://doi.org/10.1080/15422119.2014.882355, 2015.

Li, H., Shi, W., Du, Q., Zhou, R., Zhang, H., and Qin, $\mathrm{X}$ : Improved separation and antifouling properties of thin-film composite nanofiltration membrane by the incorporation of cGO, Appl. Surf. Sci., 407, 260-275, https://doi.org/10.1016/j.apsusc.2017.02.204, 2017.

Li, H., Shi, W., Zhang, H., Zhou, R., and Qin, X.: Preparation of internally pressurized polyamide thin-film composite hollow fiber nanofiltration membrane with high ions selectivity by a facile coating method, Prog. Org. Coatings, 139, 105456, https://doi.org/10.1016/j.porgcoat.2019.105456, 2020.

Linares, R. V., Li, Z., Elimelech, M., Amy, G., and Vrouwenvelder, H. (Eds.): Recent Developments in Forward Osmosis Processes, IWA Publishing, https://doi.org/10.2166/9781780408125, 2017.

Liu, X. and Ng, H. Y.: Fabrication of layered silica-polysulfone mixed matrix substrate membrane for enhancing performance of thin-film composite forward osmosis membrane, J. Memb. Sci., 481, 148-163, https://doi.org/10.1016/j.memsci.2015.02.012, 2015.

Ma, J., Xiao, T., Long, N., and Yang, X.: The role of polyvinyl butyral additive in forming desirable pore structure for thin film composite forward osmosis membrane, Sep. Purif. Technol., 242, 116798, https://doi.org/10.1016/j.seppur.2020.116798, 2020.

Maddodi, S. A., Alalwan, H. A., Alminshid, A. H., and Abbas, M. N.: Isotherm and computational fluid dynamics analysis of nickel ion adsorption from aqueous solution using activated carbon, South African J. Chem. Eng., 32, 5-12, https://doi.org/10.1016/j.sajce.2020.01.002, 2020. 
McCutcheon, J. R., McGinnis, R. L., and Elimelech, M.: A novel ammonia-carbon dioxide forward (direct) osmosis desalination process, Desalination, 174, 1-11, https://doi.org/10.1016/j.desal.2004.11.002, 2005.

Mi, B. and Elimelech, M.: Chemical and physical aspects of organic fouling of forward osmosis membranes, J. Memb. Sci., 320, 292302, https://doi.org/10.1016/j.memsci.2008.04.036, 2008.

Mohammadifakhr, M., de Grooth, J., Roesink, H. D. W., and Kemperman, A. J. B.: Forward Osmosis: A Critical Review, Processes, 8, 404, https://doi.org/10.3390/pr8040404, 2020.

Ong, R. C., Chung, T. S., Helmer, B. J., and De Wit, J. S.: Novel cellulose esters for forward osmosis membranes, Ind. Eng. Chem. Res., 51, 16135-16145, https://doi.org/10.1021/ie302654h, 2012.

Peñate, B. and García-Rodríguez, L.: Current trends and future prospects in the design of seawater reverse osmosis desalination technology, Desalination, 284, 1-8, https://doi.org/10.1016/j.desal.2011.09.010, 2012.

Raaijmakers, M. J. T. and Benes, N. E.: Current trends in interfacial polymerization chemistry, Prog. Polym. Sci., 63, 86-142, https://doi.org/10.1016/j.progpolymsci.2016.06.004, 2016.

Ren, J. and McCutcheon, J. R.: A new commercial thin film composite membrane for forward osmosis, Desalination, 343, 187193, https://doi.org/10.1016/j.desal.2013.11.026, 2014.

Ren, J. and McCutcheon, J. R.: Making Thin Film Composite Hollow Fiber Forward Osmosis Membranes at the Module Scale Using Commercial Ultrafiltration Membranes, Ind. Eng. Chem. Res., 56, 4074-4082, https://doi.org/10.1021/acs.iecr.6b04931, 2017.

Tian, M., Qiu, C., Liao, Y., Chou, S., and Wang, R.: Preparation of polyamide thin film composite forward osmosis membranes using electrospun polyvinylidene fluoride (PVDF) nanofibers as substrates, Sep. Purif. Technol., 118, 727-736, https://doi.org/10.1016/j.seppur.2013.08.021, 2013.
Vatanpour, V., Sheydaei, M., and Esmaeili, M.: Box-Behnken design as a systematic approach to inspect correlation between synthesis conditions and desalination performance of TFC RO membranes, Desalination, 420, 1-11, https://doi.org/10.1016/j.desal.2017.06.022, 2017.

Wang, Y., Guo, H., Xie, C., Zhou, N., and Fang, Z.: Study on the Influence of Interfacial Polymerization Process on Thin - Film Composite (TFC) Forward Osmosis (FO) Membrane Synthesis, Chem. Eng. Trans., 59, 121-126, https://doi.org/10.3303/CET1759021, 2017.

Xia, L., Andersen, M. F., Hélix-Nielsen, C., and McCutcheon, J. R.: Novel Commercial Aquaporin Flat-Sheet Membrane for Forward Osmosis, Ind. Eng. Chem. Res., 56, 11919-11925, https://doi.org/10.1021/acs.iecr.7b02368, 2017.

Zhao, L., Chang, P. C. Y., Yen, C., and Ho, W. S. W.: High-flux and fouling-resistant membranes for brackish water desalination, J. Memb. Sci., 425-426, 1-10, https://doi.org/10.1016/j.memsci.2012.09.018, 2013.

Zhao, S., Zou, L., Tang, C. Y., and Mulcahy, D.: Recent developments in forward osmosis: Opportunities and challenges, J. Memb. Sci., 396, 1-21, https://doi.org/10.1016/j.memsci.2011.12.023, 2012.

Zhou, Z., Lee, J. Y., and Chung, T.-S.: Thin film composite forwardosmosis membranes with enhanced internal osmotic pressure for internal concentration polarization reduction, Chem. Eng. J., 249, 236-245, https://doi.org/10.1016/j.cej.2014.03.049, 2014. 